Metabolic responses to adrenocorticotropic hormone (ACTH) vary

with life-history stage in adult male northern elephant seals.

\author{
by \\ David C. Ensminger \\ A thesis submitted to \\ Sonoma State University \\ in partial fulfillment of the requirements \\ for the degree of \\ MASTERS OF SCIENCE \\ in \\ Biology
}

Dr. Daniel E. Crocker

Dr. Nicholas R. Geist

Dr. Dorian S. Houser

$3 / 5 / 2014$

Date 
Copyright $\bigcirc 2014$

By David C. Ensminger 


\section{Authorization for Reproduction of Master's Thesis}

I grant permission for the reproduction of this thesis in its entirety, without further authorization from me, on the condition that the person or agency requesting reproduction absorb the cost and provide proper acknowledgment of authorship.

Date $3 / 5 / 2014$

Signature 


\title{
Metabolic responses to adrenocorticotropic hormone (ACTH) vary with life-history stage in adult male northern elephant seals.
}

\author{
Thesis By
}

David C. Ensminger

\begin{abstract}
Purpose of study: Strong individual and life-history variation in serum levels of glucocorticoids has been documented in many wildlife species. Less is known about the underlying variation in hypothalamic-pituitary-adrenal axis (HPA) responsiveness and its impacts on metabolism.
\end{abstract}

Procedure: . To characterize changes due to a simulated acute stress, 18 free-ranging adult male northern elephant seals were challenged with an intramuscular injection of slow release adrenocorticotropic hormone (ACTH) over 3 sample periods: early in the breeding season, after $70+$ days of the breeding fast, and during peak molt. Subjects were blood sampled every 30 minutes for 2 hrs post-injection. Breeding animals were recaptured and sampled at $48 \mathrm{hrs}$. This was not possible in molting subjects due to animal density and mobility.

Findings: In response to the ACTH injection, cortisol increased 4-6 fold in all groups, and remained elevated at $48 \mathrm{hrs}$ in early breeding subjects. ACTH was also a strong secretagogue for aldosterone, causing a 3-8 fold increase in concentration. Cortisol and aldosterone responses did not vary between groups but were significantly correlated within individuals. Endogenous ACTH was not suppressed by the challenge in any study group. The ACTH challenge resulted in elevations in plasma glucose during late breeding and molting. The ACTH challenge suppressed testosterone and thyroid hormone (T3) at $48 \mathrm{hrs}$ in early breeding males. The ACTH challenge increased plasma non-esterified fatty acids only during molting.

Conclusion: These data suggest that sensitivity of the HPA axis is maintained but the metabolic impacts of cortisol and feedback inhibition of the axis varies with life history stage. Strong impacts of the challenge on testosterone, thyroid hormone and protein sparing suggest the importance of maintaining low cortisol levels during the breeding fast. These data suggest that metabolic adaptations to extended fasting in northern elephant seals include significant alterations in tissue responses to regulatory hormones that mitigate deleterious impacts of acute or moderately sustained stress responses.

Chair: Signature

MS Program: Biology Sonoma State University Date: $3 / 5 / 2014$ 


\section{Acknowledgement}

I would like to express my special appreciation and thanks to my advisor Dr. Daniel Crocker, you have been a tremendous mentor for me. I would like to thank you for encouraging my research and for allowing me to grow as a scientist as well as a scholar. I would also like to thank my committee members, Dr. Nicholas Geist and Dr. Dorian Houser for serving as my committee members despite difficulties in distance and scheduling. I also want to thank you for your brilliant comments and suggestions at all stages of my thesis and studies. I would especially like to thank the faculty, staff, and technicians in the Biology Department at Sonoma State University. All of you have been there to support me while I obtained supplies and used equipment.

I would like to express my gratitude to my lab mates. I would like to thank Jeffrey Sharick for his constant help in the field and his knowledge and experience with elephant seals. I would like to thank Derek Somo for his help in the field and in the lab, as well as his great enthusiasm for many things. I also want to thank the whole lab, Jeff, Derek, Hannah Peck, and Sarah Codde for your amazing attitude and great sense of humor. You guys helped make the field and lab work much more enjoyable.

I would also like to thank all of my friends who supported me in writing and striving towards my goal. Your messages of encouragement always helped to bring a smile to my face.

Finally, I want to give special thanks to my family. Words cannot express how grateful I am for all of the sacrifices that you've made on my behalf. Your prayers and support for me was what sustained me thus far. 


\section{Table of contents}

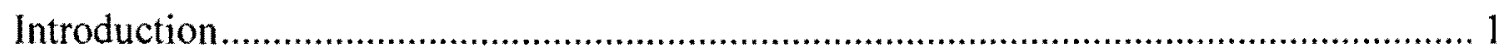

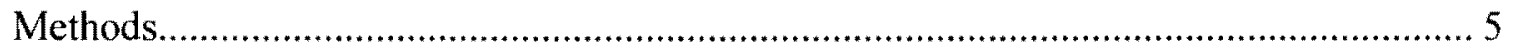

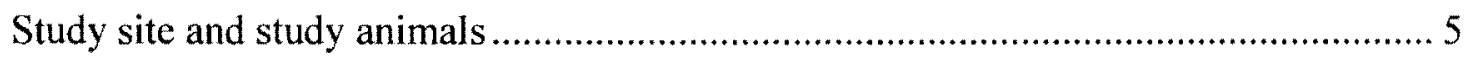

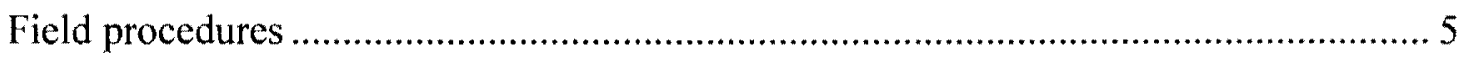

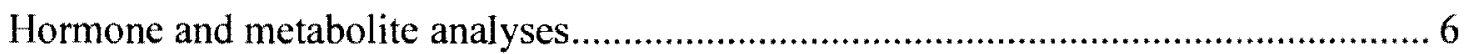

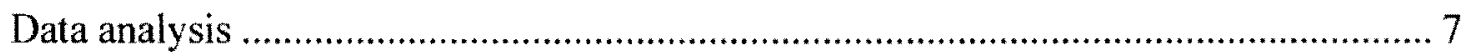

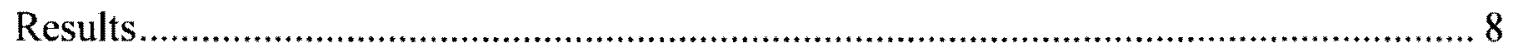

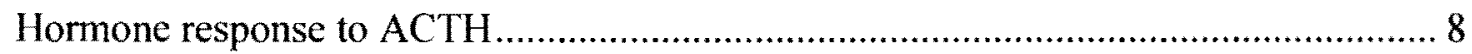

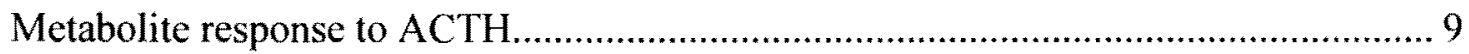

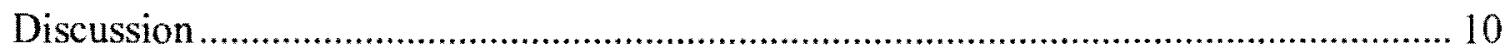

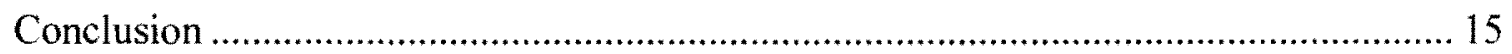

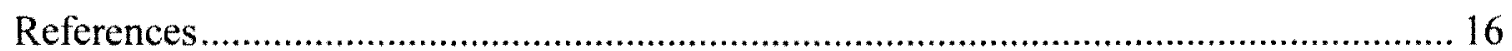


List of Tables:

Table 1. Mass, adiposity, or ACTH dose given to fasting adult male northern elephants seals. Mass and adiposity were estimated using truncated cones method and ultrasound measurements of blubber depth. . EB= early breeding, LB= late breeding, $\mathrm{MM}=$ mid-molt.

Table 2. Area under the curve (AUC) values for responses to intra-muscular $\mathrm{ACTH}$ challenge in fasting adult male northern elephant seals. $\mathrm{EB}=$ early breeding, $\mathrm{LB}=$ late breeding, $M M=$ mid-molt. Different superscripts denote significant differences between groups $(\mathrm{p}<0.05)$ based on post-hoc comparisons of means from the ANOVA.

Table 3. Baseline hormone values and values for time after the injection of $\mathrm{ACTH}$ in fasting adult male elephant seals. $\mathrm{EB}=$ early breeding, $\mathrm{LB}=$ late breeding, $\mathrm{MM}=$ midmolt. * denotes significant differences from baseline $(\mathrm{p}<0.05)$ based on post-hoc comparisons of least means squares from the GLM.

Table 4. Baseline metabolite values and values for time after the injection of $\mathrm{ACTH}$ in fasting adult male elephant seals. $\mathrm{EB}=$ early breeding, $\mathrm{LB}=$ late breeding, $\mathrm{MM}=$ mid-molt. * denotes significant differences from baseline $(p<0.05)$ based on post-hoc comparisons of least means squares from the ANOVA. 


\section{List of Figures:}

Figure 1. Time series for changes in cortisol (A), aldosterone (B), glucose (C) and lactate (D) concentrations in response to intramuscular ACTH injection in adult male NES. Time 0 represents pre-injection. Closed circle represent early breeding, open circle represents late breeding, and closed triangle represents mid-molt.

Figure 2. Comparison of area under the curve (AUC) for (A) Cortisol, (B) Glucose, (C) Aldosterone, and (D) Lactate compared to baseline following ACTH administration in NES. Different numbers denote significant differences between groups $(\mathrm{p}<0.05)$ based on post hoc comparisons of least square means from the ANOVA. Baseline is denoted by 0 . $\mathrm{EB}=$ early breeding, $\mathrm{LB}=$ late breeding, $\mathrm{MM}=$ mid-molt. $\mathrm{E}$ : Relationship between $\mathrm{AUC}$ for cortisol and aldosterone in response to an ACTH challenge in male NES. Fitted line is based on the mixed model parameter estimates : $y=17.6 x \mathrm{I}+6318, \mathrm{R}^{2}=0.32, \mathrm{~F}_{1,16}=6.7$, $\mathrm{p}=0.02$. F: Relationship between AUC for glucose and lactate in response to an ACTH challenge in male NES. Fitted line is based on mixed model parameter estimates : $y=-$ $0.98 \mathrm{x} *+11.19, \mathrm{R}^{2}=0.67, \mathrm{~F}_{1,16}=33.4, \mathrm{p}=0.0001$. Closed circle represent early breeding, open circle represents late breeding, and closed triangle represents mid-molt.

Figure 3. Comparison of pre-ACTH, $2 \mathrm{hr}$, and $48 \mathrm{hr}$ values of (A) Cortisol, (B) Aldosterone, (C) Total triiodothyronine (tT3) (D) reverse triiodothyronine (rT3), (E) Total thyroxine, and (F) Testosterone in adult male NES in response to an ACTH challenge. ${ }^{*}$ denotes signficant difference from pre-ACTH concentrations $(p<0.05)$ based on post hoc comparisons of least square means from the LMM. Black bars represent early breeding, light gray bars represent late breeding, and dark grey bars represent mid-molt. 


\section{Introduction}

All vertebrates potentially experience stressors, such as a lack of food, limited space, environmental perturbations, and conflicting interactions with conspecifics and other species. While the generalized endocrine response to stress is well studied, the terminology for describing stress responses as distinct from normal homeostatic regulation is more controversial, with several proposed frameworks. Allostasis is the maintenance of stability through changes in homeostatic set points [1]. As the cost (e.g. energetic expenditure, oxidative damage) of allostasis accumulates, the animal enters allostatic overload, which is a state where detrimental effects on the organism body and behavior are evident [1-3]. Reactive scope first defines predictive and reactive homeostasis, which allow the animal to respond to circadian, seasonal, and unpredictable variations, respectively [4]. As reactive homeostasis persists, wear and tear accumulates as a cost of maintaining physiological conditions in the reactive homeostasis range [4]. This accumulation increases the likelihood of entering homeostatic overload or failure, which potentially compromises short or long-term health [4]. Despite the differences in terminology, sustained stress can produce deleterious impacts, including suppression of immune and reproductive function [5,6]. Studies on the impacts of anthropogenic stressors to wildlife have begun to recognize that integration of various stressors, such as pollution, disturbance, alterations in food availability and others may have demographic impacts by increasing the allostatic load on individuals and affecting health and reproduction. This realization has led to the development of the field of conservation physiology [3, 7-9]. 
The primary hormonal response to stress is the activation of the hypothalamicpituitary-adrenal (HPA) axis. In response to stress, the hypothalamus releases corticotrophin-releasing hormone (CRH) [10], which stimulates the pituitary gland to release adrenocorticotropic hormone $(\mathrm{ACTH})[11] . \mathrm{ACTH}$ then acts upon the adrenal cortex, which releases corticosterioids, such as cortisol and aldosterone [12]. These adrenal hormones have wide-ranging physiological effects on metabolism, reproductive hormones, and immune function [6,13-16]. They are known to interact with and affect the concentrations or reactivity of thyroid hormones (thyroxine, T4; and triiodothyronine, T3), which themselves regulate many metabolic pathways and strongly influence wholeanimal metabolism [17]. Despite how important understanding the integration of endocrine responses to multiple stressors is to ecology and conservation, little is known about how HPA axis function and associated metabolic responses vary with life history stages in most wildlife systems. Understanding natural life-history variation in HPA axis activity and responsiveness is critical to providing a context for interpretation of baseline glucocorticoid levels [18].

Although there have been numerous studies of stress on terrestrial mammals [ 19 , 20], few studies have looked at how the HPA axis integrates stressors in wild marine mammals. Marine mammals are difficult to observe and study due to their pelagic lifestyle. Nevertheless, these animals face a number of anthropogenic stressors, such as pollution, anthropogenic noise, declining prey stocks, and boating/fisheries interactions [21-24]. Current information on the impacts of stressors to the HPA axis in marine mammals is sparse and variable across species [25-27]. Work with captive or rehabilitated Stellar sea lions and harbor seals has addressed relationships between acute 
stressors and the function of the HPA axis as reflected in fecal and serum corticosteroids [28-30]. Interestingly, while aldosterone, a key hormone in electrolyte balance, is not viewed as a major stress hormone in terrestrial mammals, it has been linked to the stress response in bottlenose dolphins (Tursiops truncatus) and harbor seals (Phoca vitulina) and has been hypothesized as a key stress hormone in marine mammals $[28,31,32]$. Levels of cortisol have been related to fasting durations, lactation, molting and breeding behavior in some phocid species [33-37]; however, data on how HPA responsiveness varies with fasting and reproductive state in the wild are limited. The combination of food abstinence and reproductive effort is a natural and predictable stressor in pinnipeds, yet little is known about the physiological response to the reproductive fasts as reflected in hormonal stress markers.

Adult male northern elephant seals (NES) provide an ideal system to investigate the alteration in HPA axis function and its metabolic impacts. Male elephant seals have the highest fasting energy expenditure, the longest fasting duration, and exhibit dramatic increases in reproductive effort relative to body size when compared to other phocids [38]. The three month breeding fast is energetically costly and incorporates terrestrial movement and combative male-male competition to establish access to females. During this time, body mass decreases by approximately $40 \%$ in dominant males and $30 \%$ in subordinate males $[39,40]$. Dominant males experience higher mating success, but at the cost of increased energy expenditure, with successful males having sustained fasting energy expenditures approaching 4 times their standard metabolic rates [38]. Males return to sea after breeding and then later undergo a second month-long haulout, during which they undergo a catastrophic molt of their pelage [41]. This also occurs while fasting and 
presumably incurs additional metabolic costs associated with tissue turnover and pelage synthesis.

Elephant seals lack a cortisol response to handling when chemically sedated. which allows measurement of basal values in natural, field conditions [42]. In marked contrast to conspecific females, cortisol remains stable across breeding in males, although highly variable among individuals [43]. This suggests that potential lipolytic benefits of elevations in cortisol [44] are secondary to other impacts on metabolism, including protein sparing. In contrast, aldosterone concentrations increased across the fast [45], which may support the hypothesis that aldosterone is an important factor in the stress response (in this case, prolonged nutrient deprivation).

Here we report changes in adrenal, thyroid and sex hormones, as well as key metabolites, in response to an $\mathrm{ACTH}$ challenge in breeding and molting adult male northern elephant seals. We measured acute effects for 2 hrs and then sampled again at 48 hrs to identify impacts of sustained ACTH stimulation. The ACTH challenge was performed to examine the responsiveness of the HPA axis and its effects on metabolism under the combined natural and predictable stressors of prolonged food and water abstinence, breeding activity and combative intrasexual competition, and the physiological constraints of molting. Our objectives were to determine hormonal markers of the stress response and how body condition and life-history stage relate to variability in the responsiveness of the HPA axis, knowledge which is necessary for understanding the potential impact of additional stressors on the seals, particularly those of anthropogenic origin. 


\section{Methods}

\section{Study site and study animals}

All animal handling procedures were approved by the Sonoma State University Institutional Animal Care and Use Committee and work was conducted under National Marine Fisheries Services marine mammal permit \#14636. Fourteen adult male northern elephant seals were studied during the breeding and molting season at Año Nuevo State Reserve. The molting period was examined in order to observe alterations in hormones and metabolites outside of the breeding season. Animals were considered adult based on body mass and development of secondary sexual characteristics [39]. If not already present, animals were marked with rear flipper tags (Dalton jumbo Roto-tags, Oxon, England) and hair dye (Lady Clairol, Stamford, CT, USA).

\section{Field procedures}

Males were sampled at three stages: in early January (Early Breeding), in late February or early March (Late Breeding), and mid-July (Mid Molt). Six males were sampled during each stage. Due to availability at the study site, 4 males were represented in both the early and late breeding samples. Each male was sedated with an intramusclular injection of $\sim 0.3 \mathrm{mg} \mathrm{kg}^{-1}$ of tiletamine $\mathrm{HCl}$ and zolazepam $\mathrm{HCl}$ (Telazol, Fort Dodge Animal Health, Fort Dodge, IA). Immobilization was maintained with bolus, intravenous injections of ketamine $\mathrm{HCl}$ (Ketaset, Fort Dodge Animal Health, Fort Dodge, IA). Blood samples were obtained from the extradural vein via an 18 gauge spinal needle and collected into chilled serum, sodium heparin, and potassium EDTA blood tubes. Samples were placed on ice until returned to the lab. After initial blood samples (pre) 
were collected, mass was visually estimated and the animal was given an intramuscular injection of $0.152 \pm 0.003 \mathrm{IU} \mathrm{kg}^{-1}$ corticotrophin LA gel (Westwood Pharmacy, Richmond, VA). ACTH dosages for the study were chosen based on pilot studies on weaned pups. Blood samples were then taken every 30 minutes until 2 hrs post-ACTH injection. Approximately $48 \mathrm{hrs}$ later $(51.1 \pm 0.4 \mathrm{hrs})$, animals were again immobilized and blood sampled. We were not able to obtain $48 \mathrm{hr}$ samples during the molt due to male movement and density. Blood samples were centrifuged for $15 \min \left(1,500 \mathrm{~g}\right.$ at $\left.4^{\circ} \mathrm{C}\right)$ and the plasma collected and frozen at $-80^{\circ} \mathrm{C}$ for later analysis. An ultrasound scanner was used to measure blubber thickness and combined with morphometrics to estimate body composition using the truncated cones method [46]. This method has been validated against isotopic measures of body composition and provides estimates of body mass that are within $5 \%$ of that obtained via direct measurement [47].

\section{Hormone and metabolite analyses}

Hormone concentrations were measured by radioimmunoassay or enzyme immunoassay using commercially available kits: cortisol, aldosterone, tT3, tT4 (Siemens, Washington, D.C., USA), ACTH, and rT3 (Alpco, Salem, NH, USA). All assays have been validated previously for use in elephant seals [48-50] except for rT3 and ACTH. ACTH and rT3 assays demonstrated parallelism of diluted samples to the standard curve and recovery of standard additions $>95 \%$. All samples were analyzed in duplicate with an average coefficient of variation for ACTH of $5.2 \%$ and the rest below $2 \%$. The ACTH assay antibodies did not bind to the synthetic ACTH preparation allowing measurement of endogenous ACTH during the procedure. 
Glucose and lactate were measured in duplicate using a YSI 2300 STAT plus auto-analyzer (YSI, Yellow Springs, OH, USA). Non-esterified fatty acids (NEFA; Wako Diagnostics, Richmond, VA, USA), blood urea nitrogen (BUN; Stanbio, Boerne, TX, USA), and beta-hydroxybutyrate ( $\beta$-HBA; Cayman Chemical Company, Ann Arbor, MI, USA) were analyzed in duplicate using enzymatic colorimetric assays. Sodium and potassium were analyzed using $\mathrm{Na}+$ and $\mathrm{K}+$ perfectION combination electrodes (Mettler Toledo, Columbus, OH, USA). Cortisol, aldosterone, ACTH, glucose and lactate were assayed for the full time series, while testosterone, tT3, rT3, tT4, BUN, $\beta$-HBA, NEFA, $\mathrm{K}+$, and $\mathrm{Na}+$ were assayed at 3 time points (pre, $120 \mathrm{~min}, 48 \mathrm{hr}$ ).

\section{Data analysis}

Linear mixed models with a repeated measures covariance structure and seal as a random effect were used to assess significant changes from baseline across the $120 \mathrm{~min}$ time series (JMP Pro 11). This approach was used for cortisol, aldosterone, ACTH, glucose, and lactate. Changes in those hormones and metabolites over the 2 hr postinjection period were also assessed as area under the curve above baseline (AUC), using the trapezoid rule in Prism 5 (Graphpad Software, San Diego, CA). AUC values were compared using linear mixed models to observe how the magnitude of the response varied across different life history stages and to identify any effects of mass, adiposity, and $\mathrm{ACTH}$ dose. For the remaining hormones and metabolites, a general linear model (GLM) was used to assess differences between the pre, $120 \mathrm{~min}$ (acute), and $48 \mathrm{hr}$ (sustained) time points within sampling periods. Mixed model linear regressions were used to assess relationships between AUC's. R2 for mixed models were calculated and regressions were visualized using the slope and intercept parameters from the mixed 
model [51]. Post-hoc differences between life history stages and time points were evaluated using Tukey's corrected differences in least square means. All data are expressed \pm standard error of the mean (SEM). Results were considered significant at $p<$ 0.05 .

\section{Results}

Mass, adipose tissue proportions, and ACTH dose are shown in Table 1. Adiposity and ACTH dose had no significant effect on any of the responses and were removed from the models. Mass had a negative effect on the acute response of cortisol to the ACTH challenge $(F 4,54.9=3.66, p=0.007)$, but did not affect any other response variables $(\mathrm{p}>0.05)$.

\section{Hormone response to $A C T H$}

Cortisol concentrations increased relative to baseline by $60 \mathrm{~min}$ in all study groups (Figure $1 \mathrm{~A} ; \mathrm{F} 4,54.9=9.67, \mathrm{p}<0.001$ ). The magnitude of cortisol release (AUC) was greater in EB males than at MM (Figure 2A; Table 2). When comparing acute and sustained responses, cortisol increased from base line at $120 \mathrm{~min}$ for all groups $(\mathrm{p}<0.05)$ but remained elevated at $48 \mathrm{hrs}$ for EB males (Figure $3 \mathrm{~A}, \mathrm{~F} 2,15 \neg=11.67, \mathrm{p}=0.0009$ ), returning to baseline by $48 \mathrm{hrs}$ in LB males.

Aldosterone increased from baseline in all study groups but the rate of increase varied (Figure 1B, F4,56.3 $=3.08, \mathrm{p}=0.02$ ). The magnitude of the aldosterone response to $\mathrm{ACTH}(\mathrm{AUC})$ was significantly higher at $\mathrm{LB}$ than at $\mathrm{MM}$ and the response at $\mathrm{EB}$ was marginally significantly higher than MM (Figure 2C, Table 2). Aldosterone showed an acute response and was elevated at $120 \mathrm{~min}$ in all groups, with values returning to 
baseline by 48 hrs (Figure 3B, Table 3, EB:F2,15-=12.89, p<0.05; LB: F2,15 $=11.12$, $\mathrm{p}=0.0011 ; \mathrm{MM}: \mathrm{F} 1,10=40.83, \mathrm{p}=0.0014)$. There was a strong positive association between cortisol and aldosterone AUC (Figure 2E, R2=0.32, F2,15 $\neg=6.7, \mathrm{p}=0.0197$ ).

Endogenous ACTH concentrations did not vary significantly from baseline across the time series for all the subjects. Testosterone had no acute alteration from baseline at $120 \mathrm{~min}$, but showed a sustained.response by being suppressed at $48 \mathrm{hrs}$ in EB males (Figure 3F, F2,15=3.44, $\mathrm{p}=0.04$ ). In LB and MM, baseline testosterone was almost undetectable, and there was no response to the ACTH challenge.

Both $\mathrm{tT} 3$ and rT3 had varying responses to the challenge, while $\mathrm{tT} 4$ remained constant at all of the time points (Figure 3C, 3D, 3E; Table 3). At 48 hours post-ACTH injection, tT3 decreased $(F 2,15 \neg=5.09, p=0.02)$ and $\mathrm{rT} 3$ increased $(\mathrm{F} 2,15 \neg=28$, $\mathrm{p}=0.0001$ ) in $\mathrm{EB}$ males. $\mathrm{MM}$ males showed an acute positive thyroid response to $\mathrm{ACTH}$ stimulation with $\mathrm{tT} 3$ being elevated at $120 \mathrm{~min}$ (Figure $3 \mathrm{C}$, Table $3 \mathrm{~F} 1,10=11.7, \mathrm{p}=0.02$ ). There was no impact of ACTH stimulation on tT4 at any time point in any group (Figure 3E).

\section{Metabolite response to $A C T H$}

Based on the time series, there were no consistent changes in glucose or lactate compared to baseline within sample groups (Figure 1C, 1D, p>0.05). However, when comparing AUCs, the magnitude of the total response for glucose was significantly higher during MM when compared to early breeding (Figure 2B, Table 2). There was a marginally significant elevation in lactate AUC in EB males compared to MM males (Figure 2D, Table 2). The ACTH challenge had an acute significant effect on both glucose and lactate during $\mathrm{MM}$, with glucose increasing $\left(\mathrm{F}_{1,10}=156.2, \mathrm{p}<0.0001\right.$, Figure 
1C) and lactate decreasing $\left(\mathrm{F}_{1,10}=48, \mathrm{p}=0.0005\right.$, Figure $\left.1 \mathrm{D}\right)$ at $120 \mathrm{~min}$. The ACTH challenge had a sustained significant effect on glucose and lactate during LB, with glucose increasing $\left(F_{2.15}=4.13, p=0.037\right.$, Table 4$)$ and lactate decreasing $\left(F_{2.15}=9.24\right.$, $\mathrm{p}=0.0024)$. When $\mathrm{AUC}_{\mathrm{glucose}}$ was regressed against $\mathrm{AUC}_{\text {lactate }}$ there was a strong negative relationship among individuals (Figure $2 F, R^{2}=0.67, F_{2.15}=33.44, p<0.0001$ ).

$\beta$-HBA and NEFA concentrations showed no response to the ACTH during breeding, but both significantly increased at $120 \mathrm{~min}$ in $\mathrm{MM}$ males (Table $4, \mathrm{~F}_{1,10}=6.92$, $\left.\mathrm{P}=0.046 ; \mathrm{F}_{1,10}=14.6, \mathrm{DF}=5, \mathrm{p}=0.012\right) . \mathrm{BUN}, \mathrm{K}+$, and $\mathrm{Na}+$ showed no response to the challenge at any time point during the different stages (Table $4, p>0.05$ ).

\section{Discussion}

Our data suggest that the HPA axis is highly responsive to ACTH stimulation across life history stages in adult male NES. ACTH dosages causing strong release of cortisol and aldosterone were an order of magnitude lower than that required for similar responses in other pinnipeds $[29,52]$. The strong sensitivity of adult male NES to ACTH contrasts the lack of cortisol response evident in response to chemical immobilization [42]. However, indirect impacts of ACTH stimulation on non-adrenal hormones and metabolites differed strongly between sampling groups. ACTH stimulation affected thyroid and sex hormones, as well as the metabolites, glucose, lactate, $\beta$-HBA, and NEFA in some, but not all life history stages. This variability in response suggests that tissue responses to cortisol are dependent on reproductive state and the length of the fasting period. 
The level of negative feedback in the cortisol response to sustained ACTH stimulation varied with the duration of the breeding fast. The sustained response at $48 \mathrm{hrs}$ in early breeding suggests weak negative feedback regulation of adrenal sensitivity to ACTH relative to that observed late in breeding. Similarly, the total cortisol response to the challenge was higher in early breeding when compared to molting. These changes may reflect the ability to enact adaptive stress responses to sustained combat and agonistic encounters early in breeding when establishment of the dominance hierarchy occurs [47]. Conversely, the reduced response and strong negative feedback evident during molting likely reflects the strong temporal regulation of cortisol during the catastrophic molt [53].

During breeding, the ACTH challenge had no significant effect on ketone, NEFA, or BUN levels. Unlike lactating females, which show a 3-fold increase in NEFA across lactation [35], males maintained consistent NEFA values across the breeding fast [54]. In contrast, we observed a modest but significant increase in NEFA and $\beta$-HBA during the molt, probably as a result of increased lipolysis and $\beta$-oxidation of fatty acids.

Nevertheless, the increase was nominal and the lack of significant ketosis in fasting NES of all life-history stages may reflect a tight coupling of beta-oxidation and tricarboxylic acid cycle activity that limits accumulation of ketogenic precursors $[44,55,56]$. Lower rates of metabolism during the molt may have allowed slightly higher rates of ketogenesis from cortisol-enhanced lipolysis. The lack of typical effects of elevated cortisol on protein catabolism and blood glucose $[57,58]$ is consistent with a reduced role for cortisol stimulation of gluconeogenesis from amino acids in fasting NES [42]. This 
feature may be critical to avoiding the loss of body protein in response to the combined stressors of breeding and fasting.

Elevations in glucose during the molt occurred 120 minutes following the administration of $\mathrm{ACTH}$, consistent with a significant increase in cortisol. However, this was not observed in either of the breeding conditions. Complicating interpretations of the findings, a significant increase in glucose was observed 48 hours after the ACTH injection during the late breeding period, but cortisol had returned to baseline values at this time. The most parsimonious explanation to this finding is that cortisol exhibited gluconeogenic effects during late breeding and during the molt, but the time-course for action varied between the two conditions. It is plausible that elevations in glucose during late breeding might have occurred after the 120-min observation period, but that elevated glucose had not returned to baseline levels by the 48 -hour measurement. Prior work in other age classes of elephant seals has demonstrated that the pancreatic release of insulin after a prolonged period of fasting is negligible and that there is an increase in insulin resistance to some tissues [59-61]. It is possible that the same trends in the insulin regulation of glucose exist in the adult males subjected to prolonged fasts. However, the lack of any change in glucose during early breeding is suggestive of a change in the responsiveness to elevations in cortisol with time fasting or changing body condition. Taken across all study subjects, the widely varying individual changes in blood glucose were closely and inversely associated with blood lactate (Figure 2F). Lactate is the primary gluconeogenic substrate in fasting, weaned NES pups [62] and reflects high rates of glucose recycling through the Cori cycle [55]. The lack of alteration in glucose/lactate in males may reflect the tight coupling of pyruvate flux to glucose production in order to 
maintain high rates of beta-oxidation without ketosis, as has been proposed for other NES age classes $[44,55,56]$.

The strong impacts of ACTH on aldosterone in all groups supports the hypothesis that aldosterone is a hormone related to the adaptive stress response in marine mammals $[31,32]$. ACTH is known to increase aldosterone secretion by a renin-angiotensin system (RAS)-independent pathway [63]. Angiotensin II can induce peripheral vasoconstriction [64-66], which may be beneficial to diving marine mammals experiencing acute stressors, but which may also result in an increase in aldosterone production. While increases in aldosterone can be beneficial in a fasting state due to decreased efflux of water and reabsorption of $\mathrm{Na}+$, it could also be a detrimental response in a hyperosmotic environment such as the ocean $[45,67,68]$.Thus, it may not be surprising that the aldosterone response showed strong negative feedback in all breeding groups suggesting a reduced response to sustained stress. Aldosterone response to ACTH was highest during late breeding when baseline aldosterone levels are highest. This suggests that pituitary stimulation may contribute independently to the strong upregulation of the RAS system seen across fasting [45]. The elevation of aldosterone had no significant effect on the electrolytes $\mathrm{Na}+$ and $\mathrm{K}+$. However, since elephant seals have a low urinary output [69] and the elevation of aldosterone was not sustained, there was likely insufficient time for elevated aldosterone to affect electrolyte concentrations.

Testosterone, while high early in breeding, showed a significant decrease in response to the $\mathrm{ACTH}$ challenge at 48 hours post-injection. The time course of the response suggests that there is potentially a negative impact on sex hormone concentrations when cortisol is maintained at high concentrations. This finding, while not 
unique [70-72], shows a potential mechanism by which sustained stress could be detrimental to male reproductive effort. It is widely accepted that testosterone plays a major role in aggression related to breeding and the establishment of territorial boundaries or challenging conspecifics for access to mates [73-76]. If the putative relationship between cortisol and testosterone holds true, then sustained elevation in cortisol early in the season may reduce reproductive effort and success through alterations in testosterone-mediated behaviors.

Similar to testosterone, thyroid hormones were only impacted by sustained ACTH stimulation early in breeding. Most thyroid hormone is released from the thyroid gland as T4, which was not affected by the ACTH challenge. At target tissues, deiodinases (D1 and D2) convert T4 into the more biologically active T3 [77]. A third deiodinase (D3) inactivates $\mathrm{T} 3$ but also convert T4 into an inactive form, rT3 [77]. The rT3 binds to T3 receptors without up-regulating gene expression, thus blocking most thyroid hormone action. Many stressors decrease D1 activity, including food limitation, illness, and high cortisol and catecholamine levels $[78,79]$. The inverse pattern in $\mathrm{tT} 3$ and $\mathrm{rT} 3$ seen in the $48 \mathrm{hr}$ sample is consistent with alterations in deiodonase activity. In adult male NES, daily energy expenditure is strongly associated with mating success with alpha males exhibiting higher rates of mass controlled energy expenditure [38]. In addition, the ability of breeding males to elevate $\mathrm{t} \mathrm{T} 3$ over the breeding fast is associated with high rates of energy expenditure but reduced protein sparing [54]. Thus, elevations in ACTH in response to sustained stressors early in breeding may influence reproductive success by reducing effort via reductions in thyroid hormone. 


\section{Conclusion}

Adrenal sensitivity to ACTH is maintained across breeding and molting in adult male NES. However, metabolic impacts of ACTH and corticosteroid release varied with life history stage. ACTH was a strong secretagogue for aldosterone in NES at all life history stages. The impacts of the ACTH stimulation on testosterone and thyroid hormones suggest that elevations in cortisol during early breeding could negatively impact reproductive effort and success. ACTH, presumably through elevation of cortisol, caused acute impacts on fatty acid and carbohydrate metabolites during molting that were not evident during breeding, suggesting a down-regulation of adipocyte and hepatic responses to cortisol during extended high-energy breeding fasts. These data suggest that metabolic adaptations to extended fasting include significant alteration in tissue responses to regulatory hormones that minimize deleterious impacts of acute or moderately sustained stress responses. Such information is critical to understanding not only how life history events are physiologically managed within the predictive scope of the stress response, but in interpreting physiological indicators of stress in animals subject to anthropogenic stressors. Without baseline information on the natural variability of stress markers within a species, it can be difficult or impossible to differentiate the relative influence of the compounding effects of natural and predictable stressors with those of human origin. 


\section{References}

[1] B. S. McEwen and J. C. Wingfield, "The concept of allostasis in biology and biomedicine," Hormones and Behavior, vol. 43, pp. 2-15, 2003.

[2] T. R. Gregory and C. M. Wood, "The effects of chronic plasma cortisol elevation on the feeding behaviour, growth, competitive ability, and swimming performance of juvenile rainbow trout," Physiological and Biochemical Zoology, vol. 72, pp. 286-295, 1999.

[3] M. Wikelski and S. J. Cooke, "Conservation physiology," Trends in Ecology \& Evolution, vol. 21, pp. 38-46, 2006.

[4] L. M. Romero, M. J. Dickens, and N. E. Cyr, "The reactive scope model-a new model integrating homeostasis, allostasis, and stress," Hormones and Behavior, vol. 55, pp. 375-389, 2009.

[5] S. Ben-Eliyahu, R. Yirmiya, J. Liebeskind, A. Taylor, and R. Gale, "Stress increases metastatic spread of a mammary tumor in rats: evidence for mediation by the immune system," Brain, Behavior, and Immunity, vol. 5, pp. 193-205, 1991.

[6] A. Tilbrook, A. Turner, and I. Clarke, "Effects of stress on reproduction in nonrodent mammals: the role of glucocorticoids and sex differences," Reviews of Reproduction. vol. 5, pp. 105-113, 2000.

[7] M. Z. Peery, S. R. Beissinger, S. H. Newman, E. B. Burkett, and T. D. Williams, "Applying the declining population paradigm: diagnosing causes of poor reproduction in the marbled murrelet," Conservation Biology, vol. 18, pp. 1088$1098,2004$.

[8] J. Regel and K. Pütz, "Effect of human disturbance on body temperature and energy expenditure in penguins," Polar Biology, vol. 18, pp. 246-253, 1997.

[9] M. Wikelski, V. Wong, B. Chevalier, N. Rattenborg, and H. L. Snell, "Galapagos Islands: Marine iguanas die from trace oil pollution," Nature, vol. 417, pp. 607$608,2002$.

[10] X.-M. Ma, A. Levy, and S. L. Lightman, "Emergence of an isolated arginine vasopressin (AVP) response to stress after repeated restraint: a study of both AVP and corticotropin-releasing hormone messenger ribonucleic acid (RNA) and heteronuclear RNA," Endocrinology, vol. 138, pp. 4351-4357, 1997.

[11] F. A. Antoni, M. C. Holmes, G. B. Makara, M. Kárteszi, and F. A. László, "Evidence that the effects of arginine-8-vasopressin (AVP) on pituitary corticotropin (ACTH) release are mediated by a novel type of receptor," Peptides, vol. 5, pp. 519-522, 1984.

[12] R. Haning and J. Tait, "In vitro effects of ACTH, angiotensins, serotonin and potassium on steroid output and conversion of corticosterone to aldosterone by isolated adrenal cells," Endocrinology, vol. 87, pp. 1147-1167, 1970.

[13] D. Brillon, B. Zheng, R. Campbell, and D. Matthews, "Effect of cortisol on energy expenditure and amino acid metabolism in humans," American Journal of Physiology-Endocrinology And Metabolism, vol. 268, pp. E501-E513, 1995.

[14] J. M. Connell and E. Davies, "The new biology of aldosterone," Journal of Endocrinology, vol. 186, pp. 1-20, 2005.

[15] S. Khani and J. A. Tayek, "Cortisol increases gluconeogenesis in humans: its role in the metabolic syndrome," Clinical Science, vol. 101, pp. 739-747, 2001. 
[16] A. G. Maule, C. B. Schreck, and S. L. Kaattari, "Changes in the immune system of coho salmon (Oncorhynchus kisutch) during the parr-to-smolt transformation and after implantation of cortisol," Canadian Journal of Fisheries and Aquatic Sciences, vol. 44, pp. 161-166, 1987.

[17] E. Danforth Jr and A. Burger, "8-The role of thyroid hormones in the control of energy expenditure," Clinics in Endocrinology and Metabolism, vol. 13, pp. 581$595,1984$.

[18] C. L. Madliger and O. P. Love, "The Need for a Predictive, Context-Dependent Approach to the Application of Stress Hormones in Conservation," Conservation Biology, vol. 28, pp. 283-287, 2014.

[19] R. Boonstra, C. J. McColl, and T. J. Karels, "Reproduction at all costs: the adaptive stress response of male arctic ground squirrels," Ecology, vol. 82, pp. 1930-1946, 2001.

[20] R. Båge, M. Forsberg, H. Gustafsson, B. Larsson, and H. Rodriguez-Martınez, "Effect of ACTH-challenge on progesterone and cortisol levels in ovariectomised repeat breeder heifers," Animal Reproduction Science, vol. 63, pp. 65-76, 2000.

[21] K. M. Brander, "Global fish production and climate change," Proceedings of the National Academy of Sciences, vol. 104, pp. 19709-19714, 2007.

[22] E. Meltzer, "Global overview of straddling and highly migratory fish stocks: The nonsustainable nature of high seas fisheries," Ocean Development \& International Law, vol. 25, pp. 255-344, 1994.

[23] S. M. Nowacek, R. S. Wells, and A. R. Solow, "Short-term effects of boat traffic on bottlenose dolphins, Tursiops truncatus, in Sarasota Bay, Florida," Marine Mammal Science, vol. 17, pp. 673-688, 2001/10// 2001.

[24] S. Tanabe, "Contamination and toxic effects of persistent endocrine disrupters in marine mammals and birds," Marine Pollution Bulletin, vol. 45, pp. 69-77, 2002.

[25] D. St Aubin and L. Dierauf, "Stress and marine mammals," CRC Handbook of Marine Mammal Medicine, pp. 253-269, 2001.

[26] D. J. St.Aubin, S. DeGuise, P. R. Richard, T. G. Smith, and J. R. Gerack, "Hematology and plasma chemistry as indcators of health and ecological status in beluga whales, Delphinapterus leucas," Arctic, vol. 54, pp. 317-331, 2001/// 2001.

[27] D. St. Aubin and J. Geraci, "Adaptive changes in hematologic and plasma chemical constituents in captive beluga whales, Delphinapterus leucas," Canadian Journal of Fisheries and Aquatic Sciences, vol. 46, pp. 796-803, 1989.

[28] F. M. D. Gulland, M. Haulena, L. J. Lowenstine, C. Munro, P. A. Graham, J. Bauman, et al., "Adrenal function in wild and rehabilitated Pacific Harbor Seals (Phoca vitulina richardii) and in seals with phocine herpesvirus-associated adrenal necrosis," Marine Mammal Science, vol. 15, pp. 810-827, 1999/// 1999.

[29] K. L. Mashburn and S. Atkinson, "Evaluation of adrenal function in serum and feces of Steller sea lions (Eumetopias jubatus): influences of molt, gender, sample storage, and age on glucocorticoid metabolism," General and Comparative Endocrinology, vol. 136, pp. 371-381, 2004.

[30] K. L. Mashburn and S. Atkinson, "Variability in leptin and adrenal response in juvenile Steller sea lions (Eumetopias jubatus) to adrenocorticotropic hormone (ACTH) in different seasons," General and Comparative Endocrinology, vol. 155, pp. $352-358,2008$. 
[31] D. S. Houser, L. C. Yeates, and D. E. Crocker, "Cold stress induces an adrenocortical response in bottlenose dolphins (Tursiops truncatus)," Journal of Zoo and Wildlife Medicine, vol. 42, pp. 565-571, 2011.

[32] C. Thomson and J. Geraci, "Cortisol, aldosterone, and leucocytes in the stress response of bottlenose dolphins, Tursiops truncatus," Canadian Journal of Fisheries and Aquatic Sciences, vol. 43, pp. 1010-1016, 1986.

[33] P. Boily, "Metabolic and hormonal changes during the molt of captive gray seals (Halichoerus grypus)," American Journal of Physiology-Regulatory, Integrative and Comparative Physiology, vol. 270, pp. R1051-R1058, 1996.

[34] G. Engelhard, S. Brasseur, A. Hall, H. Burton, and P. Reijnders, "Adrenocortical responsiveness in southern elephant seal mothers and pups during lactation and the effect of scientific handling," Journal of Comparative Physiology B, vol. 172, pp. 315-328, 2002.

[35] D. S. Houser, C. D. Champagne, and D. E. Crocker, "Lipolysis and glycerol gluconeogenesis in simultaneously fasting and lactating northern elephant seals," American Journal of Physiology - Regulatory, Integrative and Comparative Physiology, vol. 293, pp. R2376-R2381, December 1, 20072007.

[36] D. C. Lidgard, D. J. Boness, W. D. Bowen, and J. I. McMillan, "The implications of stress on male mating behavior and success in a sexually dimorphic polygynous mammal, the grey seal," Hormones and behavior, vol. 53, pp. 241$248,2008$.

[37] R. M. Ortiz, C. E. Wade, and C. L. Ortiz, "Effects of prolonged fasting on plasma cortisol and TH in postweaned norhtern elephant seal pups," American Journal of Physiology, vol. 280, pp. R790-R795, 2001.

[38] D. E. Crocker, D. S. Houser, and P. M. Webb, "Impact of body reserves on energy expenditure, water flux, and mating success in breeding male northern elephant seals," Physiological and Biochemical Zoology, vol. 85, pp. 11-20, 2012.

[39] C. J. Deutsch, M. P. Haley, and B. J. Le Boeuf, "Reproductive effort of male northern elephant seals: estimates from mass loss," Canadian Journal of Zoology, vol. 68 , pp. 2580-2593, 1990.

[40] M. P. Haley, C. J. Deutsch, and B. J. Le Boeuf, "Size, dominance and copulatory success in male northern elephant seals, Mirounga angustirostris," Animal Behaviour, vol. 48, pp. 1249-1260, 1994.

[41] B. J. Le Boeuf and R. M. Laws, Elephant Seals: Population Ecology, Behavior, and Physiology. Berkeley: University of California Press, 1994.

[42] C. D. Champagne, D. S. Houser, D. P. Costa, and D. E. Crocker, "The effects of handling and anesthetic agents on the stress response and carbohydrate metabolism in northern elephant seals," PloS one, vol. 7, p. e38442, 2012.

[43] D. E. Crocker, R. M. Ortiz, D. S. Houser, P. M. Webb, and D. P. Costa, "Hormone and metabolite changes associated with extended breeding fasts in male northern elephant seals (Mirounga angustirostris)," Comparative Biochemistry and Physiology Part A: Molecular \& Integrative Physiology, vol. 161, pp. 388-394, 2012.

[44] D. E. Crocker, C. D. Champagne, M. A. Fowler, and D. S. Houser, "Adiposity and Fat Metabolism in Lactating and Fasting Northern Elephant Seals," Advances in Nutrition: An International Review Journal, vol. 5, pp. 57-64, 2014. 
[45] R. M. Ortiz, D. E. Crocker, D. S. Houser, and P. M. Webb, "Angiotensin II and aldosterone increase with fasting in breeding adult male northern elephant seals (Mirounga angustirostris)," Physiological and Biochemical Zoology, vol. 79, pp. 1106-1112, 2006.

[46] D. E. Crocker, J. D. Williams, D. P. Costa, and B. J. Le Boeuf, "Maternal traits and reproductive effort in northern elephant seals," Ecology, vol. 82, pp. 35413555, 2001.

[47] D. E. Crocker, D. S. Houser, and P. M. Webb, "Impact of body reserves on energy expenditure, water flux, and mating success in breeding male northern elephant seals," Physiological and Biochemical Zoology, vol. 85, pp. 11-20, JanFeb 2012.

[48] R. M. Ortiz, D. S. Houser, C. E. Wade, and C. Leo Ortiz, "Hormonal changes associated with the transition between nursing and natural fasting in northern elephant seals (Mirounga angustirostris)," General and Comparative Endocrinology, vol. 130, pp. 78-83, 2003.

[49] C. D. Champagne, D. S. Houser, and D. E. Crocker, "Glucose production and substrate cycle activity in a fasting adapted animal, the northern elephant seal," Journal of Experimental Biology, vol. 208, pp. 859-868, March 1, 20052005.

[50] C. D. Champagne, S. M. Boaz, M. A. Fowler, D. S. Houser, D. P. Costa, and D. E. Crocker, "A profile of carbohydrate metabolites in the fasting northern elephant seal," Comparative Biochemistry and Physiology Part D: Genomics and Proteomics, vol. 8, pp. 141-151, 2013.

[51] L. J. Edwards, K. E. Muller, R. D. Wolfinger, B. F. Qaqish, and O. Schabenberger, "An R2 statistic for fixed effects in the linear mixed model," Statistics in Medicine, vol. 27, pp. 6137-6157, 2008.

[52] D. J. St. Aubin and J. R. Geraci, "Adrenocortical function in pinniped hyponatremia," Marine Mammal Science, vol. 2, pp. 243-250, 1986.

[53] S. Ashwell-Erickson, F. H. Fay, R. Elsner, and D. Wartzok, "Metabolic and hormonal correlates of molting and regeneration of pelage in Alaskan harbor and spotted seals (Phoca vitulina and Phoca largha)," Canadian Journal of Zoology, vol. 64, pp. 1086-1094, 1986.

[54] D. E. Crocker, R. M. Ortiz, D. S. Houser, P. M. Webb, and D. P. Costa, "Hormone and metabolite changes associated with extended breeding fasts in male northern elephant seals (Mirounga angustirostris)," Comparative Biochemistry and Physiology Part A: Molecular \& Integrative Physiology, vol. 161, pp. 388-394, 2012.

[55] C. D. Champagne, D. S. Houser, M. A. Fowler, D. P. Costa, and D. E. Crocker, "Gluconeogenesis is associated with high rates of tricarboxylic acid and pyruvate cycling in fasting northern elephant seals," American Journal of Physiology Regulatory, Integrative and Comparative Physiology, vol. 303, pp. R340-R352, August 1, 20122012.

[56] D. S. Houser, D. E. Crocker, M. S. Tift, and C. D. Champagne, "Glucose oxidation and nonoxidative glucose disposal during prolonged fasts of the northern elephant seal pup (Mirounga angustirostris)," American Journal of Physiology - Regulatory, Integrative and Comparative Physiology, vol. 303, pp. R562-R570, September 1, 20122012. 
[57] A. Fowden, J. Mijovic, and M. Silver, "The effects of cortisol on hepatic and renal gluconeogenic enzyme activities in the sheep fetus during late gestation," Journal of Endocrinology, vol. 137, pp. 213-222, 1993.

[58] M. M. Vijayan, C. Pereira, E. G. Grau, and G. K. Iwama, "Metabolic responses associated with confinement stress in tilapia: the role of cortisol," Comparative Biochemistry and Physiology Part C: Pharmacology, Toxicology and Endocrinology, vol. 116, pp. 89-95, 1997.

[59] M. A. Fowler, C. D. Champagne, D. S. Houser, and D. E. Crocker, "Hormonal regulation of glucose clearance in lactating northern elephant seals (Mirounga angustirostris)," Journal of Experimental Biology, vol. 211, pp. 2943-2949, 2008.

[60] J. A. Viscarra, J. P. Vázquez-Medina, D. E. Crocker, and R. M. Ortiz, "Glut4 is upregulated despite decreased insulin signaling during prolonged fasting in northern elephant seal pups," American Journal of Physiology-Regulatory, Integrative and Comparative Physiology, vol. 300, pp. R150-R154, 2011.

[61] J. A. Viscarra, R. Rodriguez, J. P. Vazquez-Medina, A. Lee, M. S. Tift, S. K. Tavoni, et al., "Insulin and GLP-1 infusions demonstrate the onset of adiposespecific insulin resistance in a large fasting mammal: potential glucogenic role for GLP-1," Physiological Reports, vol. 1, pp. n/a-n/a, 2013.

[62] S. Tavoni, C. Champagne, D. Houser, and D. Crocker, "Lactate flux and gluconeogenesis in fasting, weaned northern elephant seals (Mirounga angustirostris)," Journal of Comparative Physiology B, vol. 183, pp. 537-546, 2013/05/012013.

[63] R. H. Foster, C. H. MacFarlane, and M. O. Bustamante, "Recent progress in understanding aldosterone secretion," General Pharmacology: The Vascular System, vol. 28, pp. 647-651, 1997.

[64] S. G. Hood, T. Cochrane, M. J. McKinley, and C. N. May, "Investigation of the mechanisms by which chronic infusion of an acutely subpressor dose of angiotensin II induces hypertension," American Journal of PhysiologyRegulatory, Integrative and Comparative Physiology, vol. 292, pp. R1893-R1899, 2007.

[65] M. Ito, M. I. Oliverio, P. J. Mannon, C. F. Best, N. Maeda, O. Smithies, et al., "Regulation of blood pressure by the type 1A angiotensin II receptor gene," Proceedings of the National Academy of Sciences, vol. 92, pp. 3521-3525, 1995.

[66] C. N. May, "Prolonged systemic and regional haemodynamic effects of intracerebroventricular angiotensin II in conscious sheep," Clinical and Experimental Pharmacology and Physiology, vol. 23, pp. 878-884, 1996.

[67] J. W. Funder, "Aldosterone action," Annual Review of Physiology, vol. 55, pp. 115-130, 1993.

[68] D. J. Morris, "The metabolism and mechanism of action of aldosterone," Endocrine Reviews, vol. 2, pp. 234-247, 1981.

[69] S. H. Adams and D. P. Costa, "Water conservation and protein metabolism in northern elephant seal pups during the postweaning fast," Journal of Comparative Physiology B, vol. 163, pp. 367-373, 1993.

[70] S. S. Bartsh, S. D. Johnston, and D. B. Siniff, "Territorial behavior and breeding frequency of male Weddell seals (Leptonychotes weddelli) in relation to age, size, 
and concentrations of serum testosterone and cortisol," Canadian Journal of Zoology, vol. 70, pp. 680-692, 1992.

[71] P. Doerr and K. M. Pirke, "Cortisol-induced suppression of plasma testosterone in normal adult males," Journal of Clinical Endocrinology and Metabolism, vol. 43, pp. $622-629,1976$.

[72] G. Schaison, F. Durand, and I. Mowszowicz, "Effect of glucocorticoids on plasma testosterone in men," Acta Endocrinologica, vol. 89, pp. 126-131, 1978.

[73] M. C. Moore, "Testosterone control of territorial behavior: tonic-release implants fully restore seasonal and short-term aggressive responses in free-living castrated lizards," General and Comparative Endocrinology, vol. 70, pp. 450-459, 1988.

[74] J. Wingfield and M. Ramenofsky, "Testosterone and aggressive behaviour during the reproductive cycle of male birds," in Neurobiology, ed: Springer, 1985, pp. 92-104.

[75] J. C. Wingfield, R. E. Hegner, A. M. Dufty Jr, and G. F. Ball, "The" challenge hypothesis": theoretical implications for patterns of testosterone secretion, mating systems, and breeding strategies," American Naturalist, pp. 829-846, 1990.

[76] J. C. Wingfield and P. Marler, "Endocrine basis of communication in reproduction and aggression," The Physiology of Reproduction, vol. 2, pp. 1647$1677,1988$.

[77] A. C. Bianco and B. W. Kim, "Deiodinases: implications of the local control of thyroid hormone action," Journal of Clinical Investigation, vol. 116, pp. 2571$2579,2006$.

[78] E. Charmandari, C. Tsigos, and G. Chrousos, "Endocrinology of the stress response 1," Annual Reveiw of Physiology, vol. 67, pp. 259-284, 2005.

[79] C. Weissman, "The metabolic response to stress: an overview and update," Anesthesiology, vol. 73, pp. 308-327, 1990. 
Table 1. Mass, adiposity, or ACTH dose given to fasting adult male northern elephants seals. Mass and adiposity were estimated using truncated cones method and ultrasound measurements of blubber depth.

\begin{tabular}{lccc}
\hline & EB & LB & MM \\
\hline Mass $(\mathrm{kg})$ & $1813 \pm 255$ & $1198 \pm 170$ & $1435 \pm 60$ \\
Adiposity $(\%)$ & $32.6 \pm 1.7$ & $22.6 \pm 1.4$ & $33 \pm 3.3$ \\
ACTH Dose $\left(\mathrm{IU} \mathrm{kg}^{-1}\right)$ & $0.147 \pm 0.02$ & $0.150 \pm 0.01$ & $0.158 \pm 0.01$ \\
\hline
\end{tabular}

Table 2. Area under the curve $(A \cup C)$ values for responses to intra-muscular ACTH challenge in fasting adult male northern elephant seals. $\mathrm{EB}=$ early breeding, $\mathrm{LB}=$ late breeding, $\mathrm{MM}=$ midmolt. Different superscripts denote significant differences between groups $(p<0.05)$ based on post-hoc comparisons of means from the ANOVA.

\begin{tabular}{|c|c|c|c|c|}
\hline & EB & LB & MM & ANOVA Stats \\
\hline Cortisol (ug $\mathrm{dL}^{-1} \min$ ) & $1439 \pm 597$ & $1192 \pm 376^{1,2}$ & $820 \pm 317^{2}$ & $F_{3.14}=6.306, p=0.01^{*}$ \\
\hline Aldosterone $\left(\mathrm{ng} \mathrm{mL} \mathrm{m}^{-1} \mathrm{~min}\right)$ & $26.6 \pm 1.9^{1.2}$ & $35.2 \pm 4.7^{1}$ & $15.8 \pm 9.9^{2}$ & $\mathrm{~F}_{3.14}=4.703, \mathrm{p}=0.03$ * \\
\hline $\mathrm{ACTH}(\mathrm{pg} \mathrm{mL}-1 \mathrm{~min})$ & $430.7 \pm 896.3$ & $11.84 \pm 319.6$ & $604.9 \pm 511.5$ & $F_{3.14}=0.4102, p=0.86$ \\
\hline Glucose (mM min) & $-10.45 \pm 51.81^{\prime}$ & $-7.05 \pm 62.33^{1.2}$ & $61.475 \pm 31.65^{2}$ & $F_{3.14}=4.683, p=0.03 *$ \\
\hline Lactate (mM min) & $40.03 \pm 56.99$ & $4.38 \pm 83.34$ & $-49.74 \pm 26.40$ & $F_{3,14}=3.472, p=0.06$ \\
\hline
\end{tabular}


Table 3. Baseline hormone values and values for time after the injection of $\mathrm{ACTH}$ in fasting adult male elephant seals. EB=early breeding, $\mathrm{LB}=$ late breeding, $\mathrm{MM}=$ mid-molt. * denotes significant differences from baseline $(\mathrm{p}<0.05)$ based on post-hoc comparisons of least means squares from the GLM.

\begin{tabular}{|c|c|c|c|c|c|c|c|c|}
\hline & \multicolumn{3}{|c|}{ EB } & \multicolumn{3}{|c|}{ LB } & \multicolumn{2}{|c|}{$\mathrm{MM}$} \\
\hline & $0 \mathrm{~min}$ & $120 \mathrm{~min}$ & $48 \mathrm{hr}$ & $0 \mathrm{~min}$ & $120 \mathrm{~min}$ & $48 \mathrm{hrs}$ & $0 \mathrm{~min}$ & $120 \mathrm{~min}$ \\
\hline $\operatorname{Cort}\left(\mu g \mathrm{dL}^{-1}\right)$ & $7.3 \pm 1.37$ & $31.1 \pm 11.6^{*}$ & $29.2 \pm 11.5^{*}$ & $7.47 \pm 3.9$ & $29.2 \pm 3.8^{*}$ & $7.1 \pm 2.8$ & $2.9 \pm 0.8$ & $16.8 \pm 5.6^{*}$ \\
\hline Aldo $\left(p g \mathrm{dL}^{-1}\right)$ & $76 \pm 108$ & $600 \pm 345^{*}$ & $82 \pm 137$ & $334 \pm 347$ & $991 \pm 442 *$ & $335 \pm 241$ & $55.6 \pm 56.8$ & $363 \pm 121^{*}$ \\
\hline $\mathrm{ACTH}\left(\mathrm{pg} \mathrm{mL} L^{-1}\right)$ & $20.3 \pm 7.6$ & $16.4 \pm 6.9$ & $11.2 \pm 5.7$ & $13.5 \pm 4.1$ & $9.4 \pm 3.5$ & $9.0 \pm 3.9$ & $15.6 \pm 3.8$ & $21.1 \pm 6.3$ \\
\hline Test (ng dL $\left.{ }^{-1}\right)$ & $631 \pm 260$ & $509 \pm 306$ & $251 \pm 153^{*}$ & $39 \pm 62$ & $31 \pm 46$ & $4 \pm 0$ & $7.2 \pm 7.9$ & $12.9 \pm 46.2$ \\
\hline $\mathrm{TT} 4\left(\mu \mathrm{g} \mathrm{dL}^{-1}\right)$ & $3.83 \pm 0.95$ & $3.91 \pm 0.84$ & $3.21 \pm 0.91$ & $3.37 \pm 0.96$ & $3.48 \pm 0.98$ & $3.28 \pm 0.98$ & $3.12 \pm 0.40$ & $3.37 \pm 0.15$ \\
\hline TT3 $\left(\mathrm{ng} \mathrm{dL}^{-1}\right)$ & $57.0 \pm 11.8$ & $60.3 \pm 12.3$ & $40.9 \pm 9.5^{*}$ & $48.9 \pm 9.0$ & $53.6 \pm 13.3$ & $48.8 \pm 17.9$ & $75.1 \pm 7.8$ & $81.2 \pm 10.2$ \\
\hline rT3 $\left(n g \mathrm{dL}^{-1}\right)$ & $1.22 \pm 0.07$ & $1.25 \pm 0.09$ & $1.9 \pm 0.29 *$ & $1.15 \pm 0.34$ & $1.16 \pm 0.3$ & $1.21 \pm 0.23$ & $0.69 \pm 0.23$ & $0.71 \pm 0.25$ \\
\hline
\end{tabular}


Table 4. Baseline metabolite values and values for time after the injection of ACTH in fasting adult male elephant seals. EB=early breeding, $L B=$ late breeding, $M M=$ mid-molt. * denotes significant differences from baseline $(p<0.05)$ based on post-hoc comparisons of least means squares from the ANOVA.

\begin{tabular}{ccccccccc}
\hline & \multicolumn{9}{c}{ EB } & \multicolumn{1}{c}{ LB } \\
\cline { 2 - 8 } & $0 \mathrm{~min}$ & $120 \mathrm{~min}$ & $48 \mathrm{hrs}$ & $0 \mathrm{~min}$ & $120 \mathrm{~min}$ & $48 \mathrm{hrs}$ & $0 \mathrm{~min}$ & $120 \mathrm{~min}$ \\
\hline Glucose $(\mathrm{mM})$ & $7.62 \pm 0.37$ & $7.78 \pm 0.57$ & $7.05 \pm 0.88$ & $6.83 \pm 0.89$ & $6.79 \pm 0.74$ & $7.82 \pm 0.36^{*}$ & $5.72 \pm 0.64$ & $6.85 \pm 0.7^{*}$ \\
Lactate $(\mathrm{mM})$ & $1.61 \pm 0.65$ & $1.82 \pm 0.52$ & $2.05 \pm 1.1$ & $3.09 \pm 0.85$ & $3.29 \pm 0.63$ & $1.7 \pm 0.58^{*}$ & $4.63 \pm 0.64$ & $3.71 \pm 0.8^{*}$ \\
B-HBA (mM) & $0.33 \pm 0.09$ & $0.34 \pm 0.1$ & $0.42 \pm 0.09$ & $0.44 \pm 0.06$ & $0.42 \pm 0.06$ & $0.42 \pm 0.07$ & $0.12 \pm 0.02$ & $0.14 \pm 0.01^{*}$ \\
NEFA (mM) & $0.80 \pm 0.23$ & $1.02 \pm 0.14$ & $0.98 \pm 0.21$ & $0.73 \pm 0.24$ & $0.90 \pm 0.33$ & $0.60 \pm 0.30$ & $0.78 \pm 0.07$ & $0.95 \pm 0.12^{*}$ \\
BUN (mM) & $14.1 \pm 3.1$ & $15.2 \pm 3.5$ & $13.5 \pm 3.1$ & $16.0 \pm 3.2$ & $18.4 \pm 3.6$ & $22.5 \pm 6.4$ & $39.9 \pm 2.5$ & $41.1 \pm 2.8$ \\
K+ (mM) & $4.34 \pm 0.40$ & $4.32 \pm 0.15$ & $4.26 \pm 0.13$ & $3.59 \pm 0.26$ & $3.65 \pm 0.41$ & $3.64 \pm 0.11$ & $4.3 \pm 0.26$ & $3.64 \pm 0.11$ \\
$\mathrm{Na}+(\mathrm{mM})$ & $138.7 \pm 2.9$ & $138.7 \pm 2.3$ & $139.1 \pm 1.4$ & $139.3 \pm 1.9$ & $139.4 \pm 3.1$ & $139 \pm 2.1$ & $140.8 \pm 2.3$ & $140.1 \pm 2.3$ \\
\hline
\end{tabular}


Figure 1. Time series for changes in cortisol (A), aldosterone (B), glucose (C) and lactate (D) concentrations in response to intramuscular ACTH injection in adult male NES. Time 0 represents pre-injection. Closed circle represent early breeding, open circle represents late breeding, and closed triangle represents mid-molt
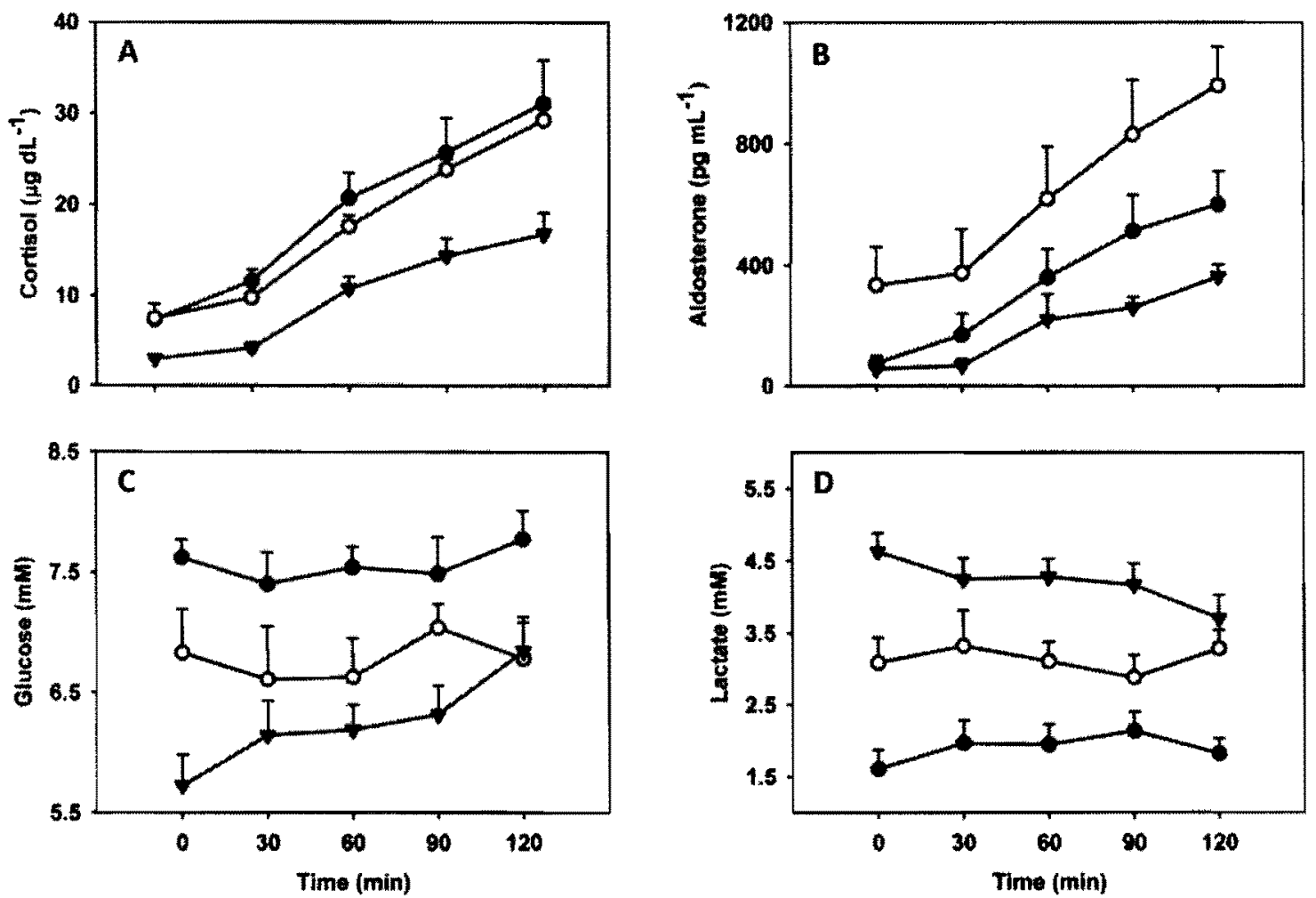
Figure 2. Comparison of area under the curve (AUC) for A: Cortisol, B: Glucose, C: Aldosterone, and D: lactate compared to baseline following ACTH administration in NES. Different numbers denote significant differences between groups $(p<0.05)$ based on post hoc comparisons of least square means from the ANOVA. Baseline is denoted by 0 . $\mathrm{EB}=$ early breeding, $\mathrm{LB}=$ late breeding, $\mathrm{MM}=$ mid-molt. $\mathrm{E}$ : Relationship between $\mathrm{AUC}$ for cortisol and aldosterone in response to an ACTH challenge in male NES. Fitted line is based on the mixed model parameter estimates $: \mathrm{y}=17.6 \mathrm{xl}+6318, \mathrm{R} 2=0.32, \mathrm{~F} 1,16=6.7$, $\mathrm{p}=0.02$. F: Relationship between AUC for glucose and lactate in response to an $\mathrm{ACTH}$ challenge in male NES. Fitted line is based on mixed model parameter estimates : $y=-$ $0.98 x^{*}+11.19, \mathrm{R} 2=0.67, \mathrm{~F} 1,16=33.4, \mathrm{p}=0.0001$. Closed circle represent early breeding, open circle represents late breeding, and closed triangle represents mid-molt.
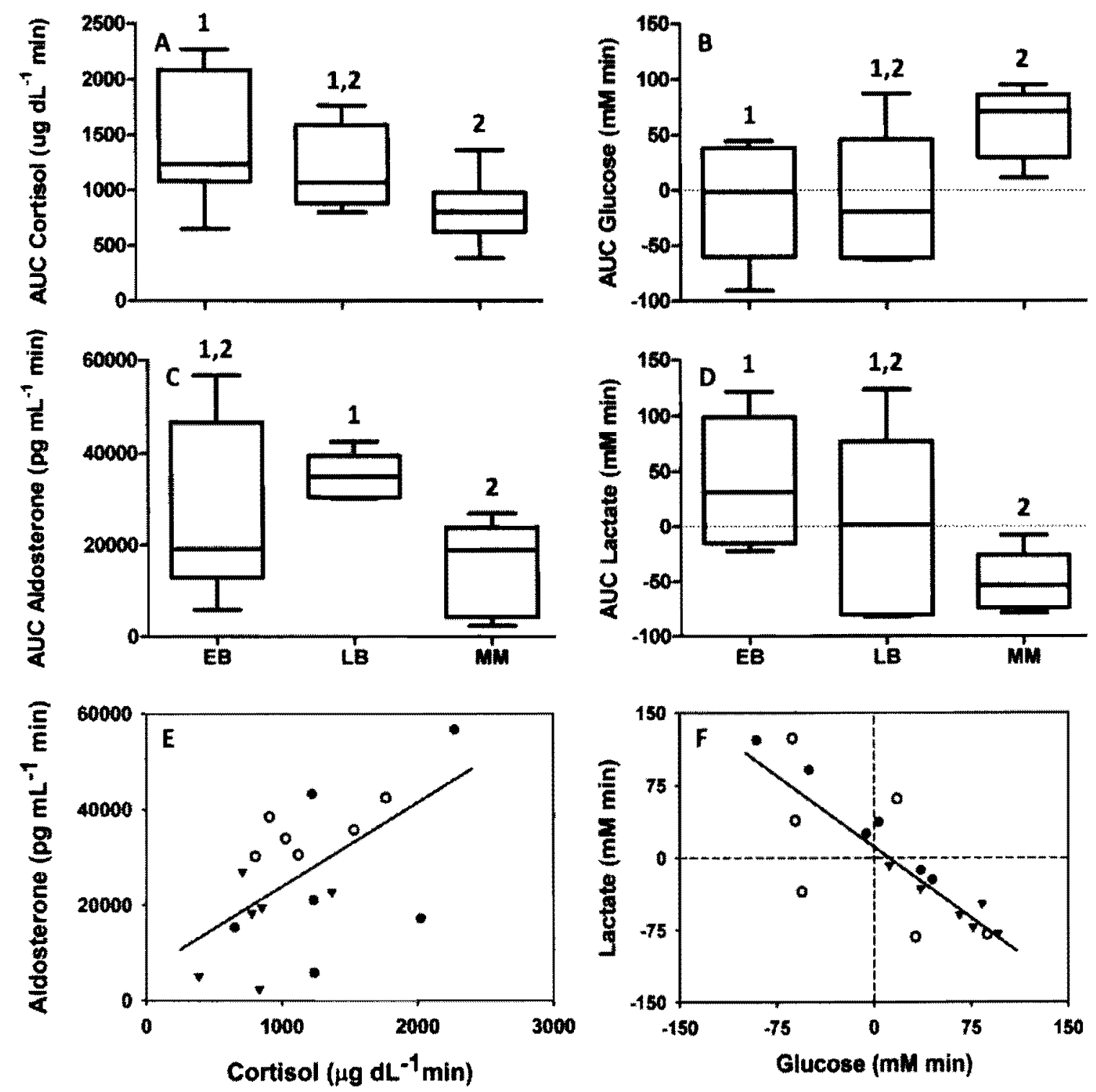
Figure 3. Comparison of pre-ACTH, $2 \mathrm{hr}$, and $48 \mathrm{hr}$ values of A: Cortisol, B:

Aldosterone, C: Total triiodothyronine (tT3) D: reverse triiodothyronine (rT3), E: Total thyroxine, and F: Testosterone in adult male NES in response to an ACTH challenge. * denotes significant difference from pre-ACTH concentrations $(\mathrm{p}<0.05)$ based on post hoc comparisons of least square means from the LMM. Black bars represent early breeding, light gray bars represent late breeding, and dark grey bars represent mid-molt.
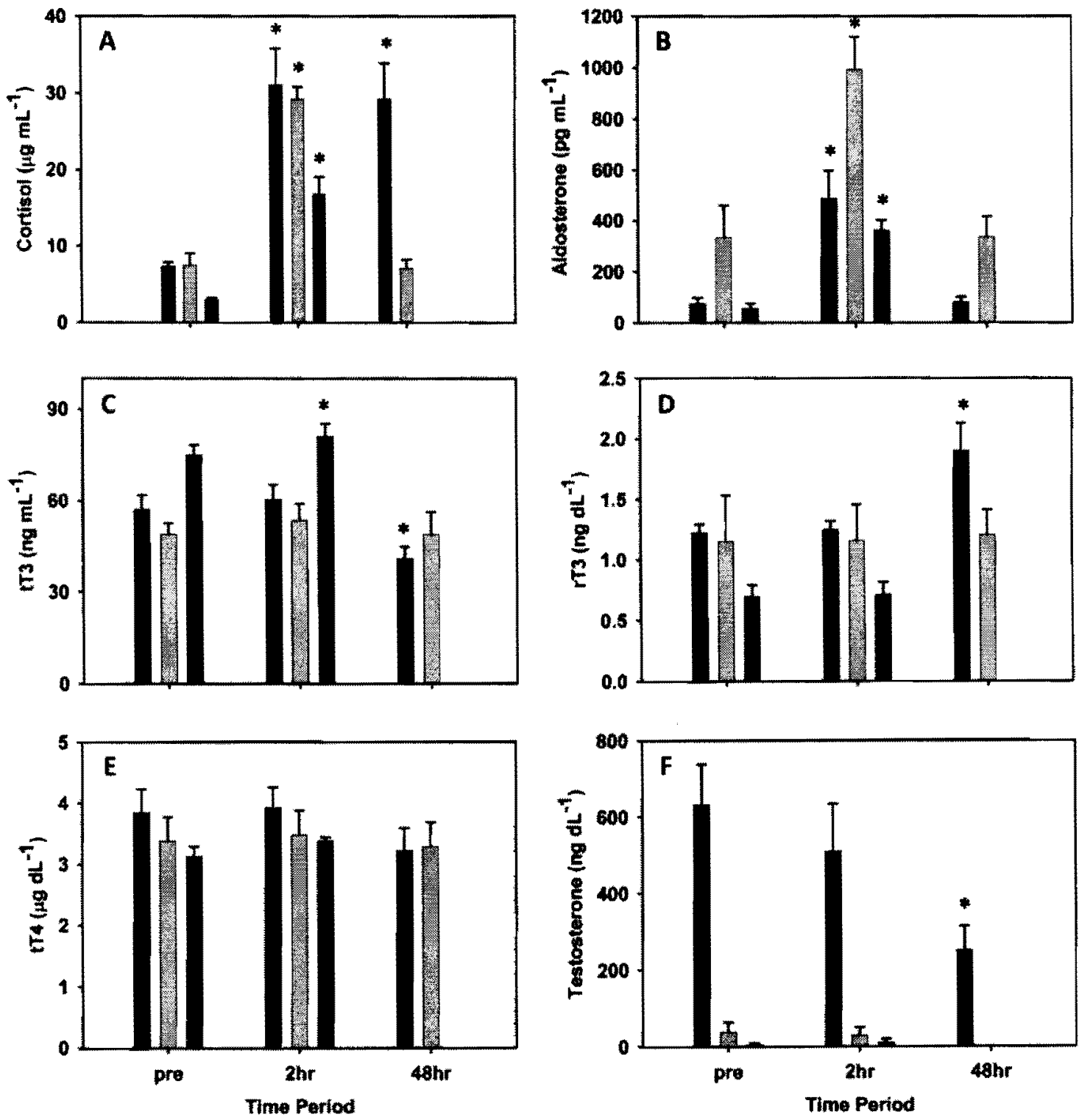